\title{
Ongoing outbreak of invasive and non-invasive disease due to group A Streptococcus (GAS) type emm66 among homeless and people who inject drugs in England and Wales, January to December 2016
}

N Bundle ${ }^{123}$, L Bubba ${ }^{45}$, J Coelho ${ }^{6}$, R Kwiatkowska ${ }^{279}$, R Cloke ${ }^{8}$, S King ${ }^{9}$, J Rajan-lyer ${ }^{8}$, M Courtney-Pillinger ${ }^{8}$, CR Beck ${ }^{2}$, V Hope $^{10}{ }^{12}$, T Lamagni $^{11}$, CS Brown ${ }^{6}$, D Jermacane ${ }^{23}$, R Glass ${ }^{12}$, M Desai ${ }^{12}$, M Gobin ${ }^{2}$, S Balasegaram ${ }^{2}$, C Anderson ${ }^{2}$

1. United Kingdom Field Epidemiology Training Programme, Public Health England, United Kingdom

2. Field Epidemiology Services, National Infection Service, Public Health England, London and Bristol, United Kingdom

3. European Programme for Intervention Epidemiology Training (EPIET), European Centre for Disease Prevention and Control (ECDC), Stockholm, Sweden

4. Reference Department Microbiology Services Division, National Infection Service, Public Health England, London, United Kingdom

5. European Programme for Public Health Microbiology Training (EUPHEM), European Centre for Disease Prevention and Control (ECDC), Stockholm, Sweden

6. Respiratory and Vaccine Preventable Bacteria Reference Unit, National Infection Service, Public Health England, London, United Kingdom

7. United Kingdom Public Health Specialty Training Programme

8. Public Health England South East, Horsham, United Kingdom

9. Public Health England South West, Bristol, United Kingdom

10. Public Health Institute, Liverpool John Moores University, Liverpool, United Kingdom

11. Healthcare-Associated Infection \& Antimicrobial Resistance Department, National Infection Service, Public Health England, London, United Kingdom

12. HIV and STI Department, National Infection Service, Public Health England, London, United Kingdom

Correspondence: Nicholas Bundle (nick.bundle@phe.gov.uk)

Citation style for this article:

Bundle N, Bubba L, Coelho J, Kwiatkowska R, Cloke R, King S, Rajan-lyer J, Courtney-Pillinger M, Beck CR, Hope V, Lamagni T, Brown CS, Jermacane D, Glass R, Desai M, Gobin M, Balasegaram S, Anderson C. Ongoing outbreak of invasive and non-invasive disease due to group A Streptococcus (GAS) type emm66 among homeles and people who inject drugs in England and Wales, January to December 2016. Euro Surveill. 2017;22(3):pii=30446. DOI: http://dx.doi.org/10.2807/1560-7917.

ES.2017.22.3.30446

Article submitted on 16 December 2016 / accepted on 19 January 2017 / published on 19 January 2017

We report an outbreak of invasive and non-invasive disease due to an unusual type of Streptococcus pyogenes(group A Streptococcus, emm66) among a vulnerable, largely homeless population in southern England and Wales, detected in September 2016. Twenty-seven confirmed cases were subsequently identified between 5 January and 29 December 2016; 20 injected drugs and six reported problematic alcohol use. To date, we have ruled out drug-related vehicles of infection and identified few common risk factors.

On 26 September 2016, a cluster of invasive disease caused by Streptococcus pyogenes (group A Streptococcus, GAS) was detected among people who inject drugs (PWID) or who were street homeless in a town in the south of England. A local outbreak control team (OCT) was set up to investigate this cluster which included infections due to emm66, a GAS type rarely identified by the Public Health England (PHE) Respiratory and Vaccine Preventable Bacteria Reference Unit (RVPBRU) in previous years. Additional cases of both invasive (iGAS) and non-invasive disease due to GAS type emm66 were retrospectively identified in the RVPBRU database and a review of local health protection team (HPT) case records revealed the majority of them to have occurred among PWID, those homeless, or reporting problematic alcohol use. A national OCT was convened on 14 October 2016 with representation from local and national health protection, epidemiology and microbiology services. We describe the ongoing outbreak of invasive and non-invasive disease caused by GAS emm66 as at 12 January 2017.

\section{Epidemiological investigation and microbiological characterisation}

The outbreak case definition is individuals with confirmed GAS type emm66 infection (invasive and noninvasive) in England and Wales with a sample date from January 2016, who are, or are epidemiologically linked to someone who is, homeless, PWID or reporting problematic alcohol use.

Cases were identified from notifications made to HPTs in England and Wales [1,2] and from typed isolates from RVPBRU. Invasive disease was defined through the isolation of GAS from normally sterile sites. 
Outbreak cases of group A Streptococcus type emm66 infection, by week of sample date and town of residence, England and Wales, $2016(\mathrm{n}=27)$

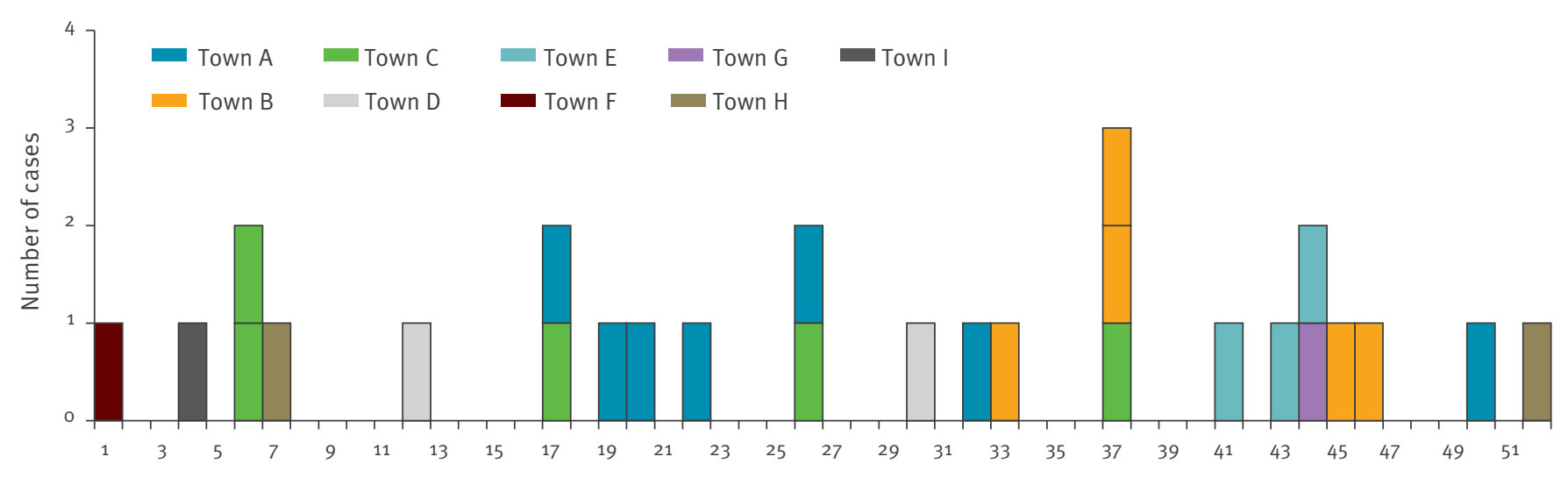

ISO week of date when sample was taken in 2016

ISO: International Organization for Standardization.

We gathered information on lifestyle risk factors, including alcohol use and vehicles of infection related to drug use or homelessness, potential venues and modes of transmission, from a hypothesis-generating questionnaire. Questions covered accommodation, social contacts and drug use, including injection practices, in the seven days before illness and in the past year. We used validated questions, where possible, from the United Kingdom (UK)'s Unlinked Anonymised Monitoring Survey (UAM) of PWID [3] so as to provide comparator data. Questionnaires were completed by local HPTs and homeless/drug outreach services. We also summarised information obtained from outreach services, case records, local investigations and laboratory surveillance.

Initial testing for GAS usually occurs at local hospital laboratories that forward most isolates from invasive infections to RVPBRU for further characterisation. In this outbreak, laboratories were also encouraged to forward isolates from non-invasive infections in people who might meet the case definition. GAS types were determined by the emm sequence typing method [4], which compares the emm sequences obtained by PCR and Sanger sequencing to those available in the emm database using the BLAST algorithm [5].

\section{Description of the outbreak}

RVPBRU identified 30 emm66 infections in 2016, of which 27 (iGAS: 20; non-invasive GAS: 7) met the outbreak case definition with samples taken between 5 January and 29 December 2016 (Figure 1).

As at 12 January 2017, 12 questionnaires were returned; ten fully completed from case interviews and two partially completed from case information and interview with a homeless outreach worker. Demographic and clinical characteristics of cases are summarised in Table 1.

The cases were predominantly clustered across a $280 \mathrm{~km}$ span of southern England and Wales, bounded by Towns $B$ and $C$ to the east and Town $H$ to the west. Nine towns in total had cases. Towns A, C, D, E, F, G and $\mathrm{H}$ are located along, or near to, a major road and rail transport corridor that connects London and South Wales. Town B is linked to this corridor via Town C. Town I is situated in the north of England. (Figure 2).

In Town A, all seven cases were linked through drug use or access to the same community drug service and six of these cases were also clustered in time (AprilAugust 2016). All cases in Town B were street homeless, with three cases linked in time (August-September) and through anecdotal reports of sharing needles or drugs. All cases in Town C appeared unconnected. A common homeless hostel linked cases in Town D and information is pending about Town E. There is no known staff travel between hostels in different towns. There was social contact by one case between Towns $A$ and $C$ whose onset was among the latest in each of these locations. Another Town $\mathrm{C}$ case reported spending time, before onset of illness, in Town J, located $40 \mathrm{~km}$ from Town A.

Among the ten cases interviewed, the median delay between the sample and interview date was 104.5 days (range 3-263). Six of these interviewees were retrospectively identified cases and a much shorter median delay of 8.5 days (range $3-27$ ) was seen among the four prospectively identified cases. (Table 2 ).

All ten cases reported drug use in the seven days before illness, with the eight PWIDs mainly using 


\section{FIGURE 2}

Network map summarising links between cases by town, place and social contact, outbreak of group A Streptococcus type emm66, England and Wales, 5 January-29 December $2016(\mathrm{n}=27)$

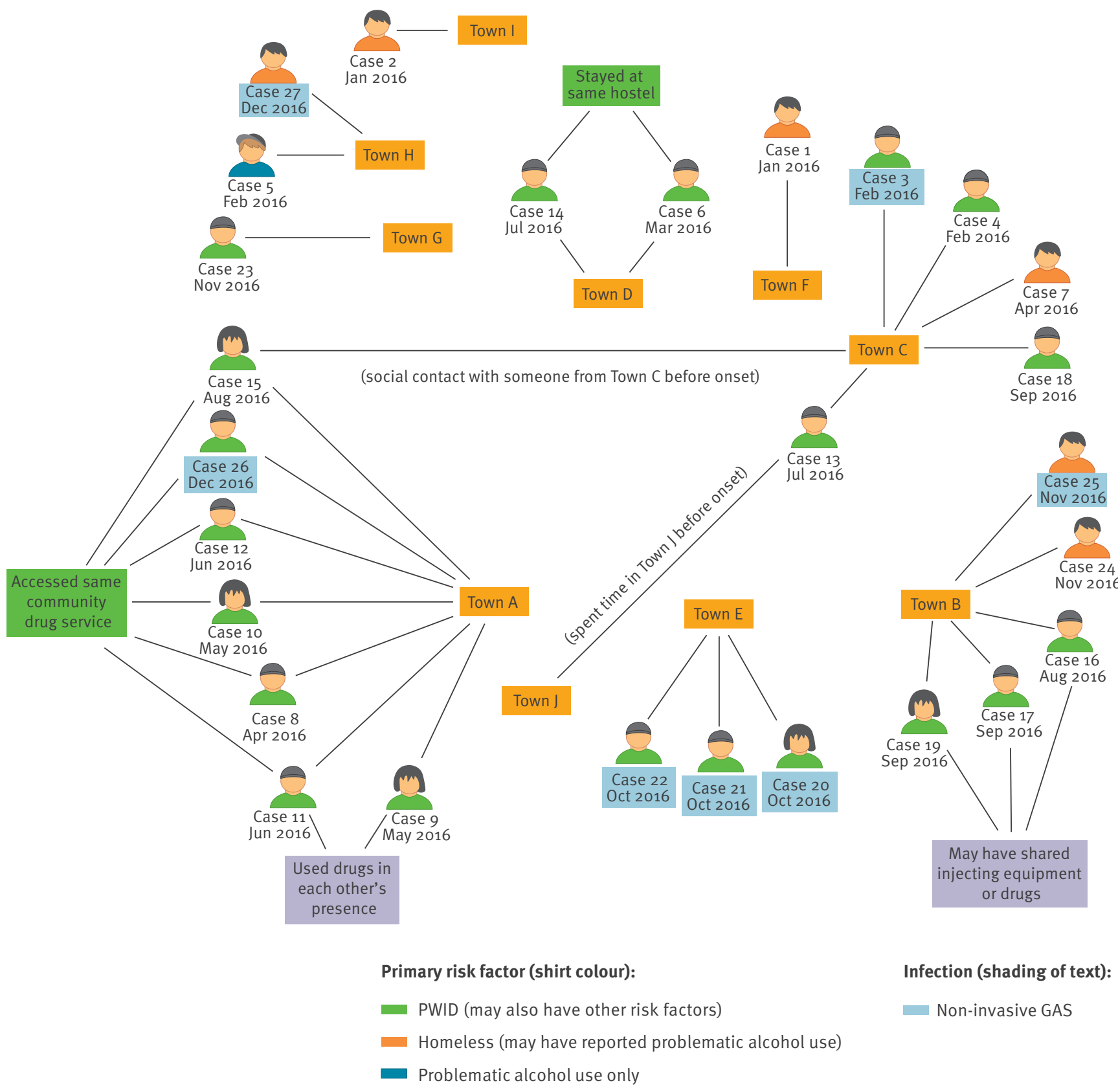

GAS: group A Streptococcus; PWID: people who inject drugs.

heroin and crack. Some reported sharing of spoons/ mixing containers and filters, but not needles. Two PWIDs linked to different towns ( $A$ and $D$ ) reported having changed dealers in the seven days before illness onset. Otherwise, there was no notable change in reported injecting behaviour or other drug use compared with that during the year prior to questionnaire administration.

\section{Control measures}

We cascaded a health alert on 2 November 2016 to HPTs, microbiology services and local authorities working with affected populations to highlight the need for early detection of infection, swabbing of PWID for non-invasive GAS, referral of isolates to RVPBRU for typing, emphasising safe and hygienic injection practices when communicating with PWIDs and ensuring their easy access to needle and syringe programmes (NSP).

In towns with multiple cases, local OCTs reviewed the policies and practices of affected NSP and homeless hostels around injecting, infection control and environmental cleaning, comparing them against national 
TABLE 1

Features of outbreak group A Streptococcus type emm66 cases, England and Wales, 5 January-29 December 2016 $(\mathrm{n}=27)$

\begin{tabular}{|c|c|}
\hline Total cases & $\mathrm{n}$ \\
\hline \multicolumn{2}{|l|}{ Demographics and risk factors ${ }^{a}$} \\
\hline Male & 22 \\
\hline Median age (range) in years & $38(29-56)$ \\
\hline Homeless at time of illness onset & 20 \\
\hline Street homeless at time of illness onset & 13 \\
\hline People who inject drugs & 20 \\
\hline Problematic alcohol use & 6 \\
\hline \multicolumn{2}{|l|}{ Initial clinical presentation } \\
\hline Abscess & 7 \\
\hline Injection site infection & 6 \\
\hline Septic arthritis & 3 \\
\hline Bacteraemia & 3 \\
\hline Muscle or deep tissue infection & 3 \\
\hline Cellulitis & 2 \\
\hline Unspecified soft tissue infection & 1 \\
\hline Necrotising fasciitis & 1 \\
\hline Pneumonia & 1 \\
\hline \multicolumn{2}{|l|}{ Diagnosis, outcomes and co-infection ${ }^{a}$} \\
\hline Invasive GAS infection & 20 \\
\hline $\begin{array}{l}\text { Non-invasive GAS infection (including three } \\
\text { severe infections) }\end{array}$ & 7 \\
\hline Hospitalisation & 21 \\
\hline Amputation & 1 \\
\hline Died due to GAS infection & 1 \\
\hline Previously tested positive for hepatitis C & 15 \\
\hline Previously tested positive for hepatitis B & 1 \\
\hline
\end{tabular}

GAS: group A Streptococcus.

a More than one answer could be chosen.

guidance [1,2] and published evidence [6]. Teaching sessions were organised for frontline homeless service providers to raise awareness of GAS infection and infection control measures. Targeted communications to raise awareness of early symptoms and to encourage prompt healthcare attendance in the event of skin problems at injection sites were disseminated via general practitioners, local authorities, pharmacies and included in the equipment packs of one NSP.

\section{Discussion}

Large outbreaks of GAS type emm66 have not previously been described. In this outbreak although the cases occurred disproportionately among PWID, transmission appears unrelated to drug usage. Illness occurred over an 11-month period, cases were representative of the wider UK PWID population in terms of sex, age and hepatitis C prevalence [3] and we identified no notable changes in drug using practice in the period before illness. The age and sex distribution of cases, low mortality (only one case died) and predominance of abscesses and injection site infections were also broadly consistent with the pattern seen among iGAS cases in PWID in England in the early 2000 s [7,8].

We have identified potential transmission clusters within three of the affected towns but only limited epidemiological links between cases in different towns. Travel along the major transport routes connecting the towns remains a plausible hypothesis for the disease propagation observed. Whole genome sequencing (WGS) of outbreak and historic emm66 isolates held by RVPBRU may have potential to identify links between cases, improve the specificity of our case definition and establish whether the outbreak strain has any genes suggestive of increased virulence. However, the role of WGS in an outbreak of such a rare GAS type, with limited availability of historical isolates for comparison, is the subject of ongoing discussion.

Difficulties in interviewing the affected population, especially for cases identified retrospectively, and accurately establishing networks of contacts pose challenges for investigation and control. Close coordination between local HPTs and frontline drug/homeless outreach services has been essential for accessing the affected population and implementing control measures to date.

The proportion of iGAS infections reported to RVPBRU attributed to PWID (other risk factors are not recorded) has increased annually since 2013 from $0.2 \%$ to $1.7 \%$ in 2016. A previous rise, dominated by GAS type emm83, was recorded in the early 2000 , with PWID accounting for $20 \%$ of all iGAS cases in England and Wales at its peak in 2003 [8,9]. The requirement for iGAS isolate submission has not changed during 2013-16 and it is unclear whether the increase represents a true change in disease burden among PWID, increased awareness of injection site infections and/or access to healthcare, or if it is an artefact of increased PWID reporting on referral forms. Prior to the increase in GAS type emm66 in 2016, the most common type seen among PWID with iGAS was emm94, with six cases in the entire period 2010-15 and two cases in 2016. GAS type emm66 is very uncommon in high income settings such as Europe and North America [10-12]. It comprised 1.3\% of iGAS isolates submitted to RVPBRU for typing in 2016; an increase from $0.16 \%$ of the isolates during $2010-15$. There is very limited mention of type emm66 in the literature beyond a single case in Hungary in 2004-05 [13] and sequencing of an isolate from within a cluster of 13 cases in France in 2009-13 [14]. The rapid increase in the number of type emm66 iGAS cases detected in England and Wales in 2016 and the high proportion of PWID among cases leave us confident that this is a genuine outbreak. So far, despite the wide geography, the outbreak has been limited to this vulnerable marginalised group and emm66 may now be the dominant circulating type within that population. Unfortunately, there are no data on background carriage rates of emm types within different groups. 


\section{TABLE 2}

Summary of responses from interviews with group A Streptococcus type emm66 outbreak cases, England and Wales, $2016(n=10)$

\begin{tabular}{|c|c|}
\hline Positive responses & $\mathrm{n}$ \\
\hline \multicolumn{2}{|l|}{$\begin{array}{l}\text { Country of origin, accommodation and contacts in the seven } \\
\text { days before illness onset }{ }^{\mathrm{a}}\end{array}$} \\
\hline Born in the UK & 9 \\
\hline Stayed in a house or flat (own, partner's or friend‘s) & 6 \\
\hline Stayed outside (street, park or abandoned building) & 5 \\
\hline Stayed in a squat & 3 \\
\hline Stayed in a hostel & 1 \\
\hline Accessed community drug or health services & 6 \\
\hline $\begin{array}{l}\text { Knew someone suffering from the same illness, infection or } \\
\text { sore throat at a similar time }\end{array}$ & 5 \\
\hline $\begin{array}{l}\text { Visited or spent time with someone from another part of the } \\
\text { UK }\end{array}$ & 3 \\
\hline \multicolumn{2}{|l|}{$\begin{array}{l}\text { Drug use and behaviour in the seven days before illness } \\
\text { onset }^{\text {a }}\end{array}$} \\
\hline Any drug use & 10 \\
\hline Injecting drug use ${ }^{a}$ & 8 \\
\hline Heroin & 8 \\
\hline Crack & 6 \\
\hline $\begin{array}{l}\text { Used spoons/mixing containers or filters previously used by } \\
\text { someone else }\end{array}$ & 4 \\
\hline Changed drug dealer & 2 \\
\hline Other drug use ${ }^{a}$ & 8 \\
\hline Smoked crack & 7 \\
\hline Smoked, chased or snorted heroin & 6 \\
\hline Smoked or swallowed cannabis & 3 \\
\hline Snorted cocaine & 2 \\
\hline Swallowed non-prescribed benzodiazepines & 2 \\
\hline
\end{tabular}

UK: United Kingdom.

a More than one answer could be chosen.

There is no indication of a drug-related vehicle of infection and we can conclude that there have been no common risk factors identified to date other than those listed in the case definition. These are all associated with increased vulnerability to iGAS and may result in protracted incidence as previously described in a Canadian GAS type emm59 outbreak [15]. We must therefore maintain increased awareness of the early signs of GAS infection among the affected population and those that serve them. As our investigations continue, we expect lessons from this outbreak to emerge around transmission routes and effectiveness of control measures that will have relevance to other countries facing GAS outbreaks in vulnerable, under-served populations.

\section{Acknowledgements}

We would like to thank all the cases for their cooperation with this investigation and the following people, listed in alphabetical order, for their role in investigating the outbreak:
Adam Spencer, Brendan Mason, Chitra Arumugam, Chris Williams, Claude Seng, Dan Lewer, David Wainfur, Helen Trudgeon, Ian Greenwood, Jennifer Duffy, Jill Bonney, Julie Mann, Kathryn Wolf, Phil McHale, Laura Pomeroy, Liz Loosemore, Meera Chand, Mike Burrell, Oluwakemi Olufon, Richard Packer, Roger Daniel, Sarah Kennedy, Simon Padfield, Siôn Lingard, Sue Morgan, Victoria Moir, Zoe Gibson.

The Blast-emm database is hosted by Centres for Disease Control and Prevention (https://www2a.cdc.gov/ncidod/biotech/strepblast.asp)

NB is funded by UK Field Epidemiology Training Programme (FETP), Public Health England, LB is funded by European Programme for Public Health Microbiology Training (EUPHEM), European Centre for Disease Prevention and Control (ECDC), Stockholm, Sweden and DJ is funded by European Programme for Intervention Epidemiology Training (EPIET), European Centre for Disease Prevention and Control $(E C D C)$, Stockholm, Sweden.

We would like to thank Sooria Balasegaram (FETP), Ioannis Karagiannis (FETP), Androulla Efstratiou (EUPHEM), Aftab Jasir (EUPHEM), Isabel Oliver (EPIET) and Lisa Hansen (EPIET) for the support provided to the fellows that they supervise.

\section{Conflict of interest}

None declared.

\section{Authors' contributions}

All authors contributed to data collection and interpretation. Nick Bundle undertook the data analysis, drafted and revised the manuscript based on all authors' contributions.

\section{References}

1. Health Protection Agency (HPA). Group A Streptococcus Working Group. Interim UK guidelines for management of close community contacts of invasive group A streptococcal disease. Commun Dis Public Health. 2004;7(4):354-61.PMID: 15786581

2. Steer JA, Lamagni T, Healy B, Morgan M, Dryden M, Rao $B$, et al. Guidelines for prevention and control of group A streptococcal infection in acute healthcare and maternity settings in the UK. J Infect. 2012;64(1):1-18. DOI: 10.1016/j. jinf.2011.11.001 PMID: 22120112

3. Public Health England (PHE). Unlinked Anonymous Monitoring Survey of People Who Inject Drugs in contact with specialist services: data tables. Surveillance Update: July 2016. London: PHE. Available from: https://www.gov.uk/government/ uploads/system/uploads/attachment data/file/537598/UAM Survey of PWID 2016 data_tables_with_2015 data FINAL. pdf

4. Facklam R, Beall B, Efstratiou A, Fischetti V, Johnson D, Kaplan $E$, et al. emm typing and validation of provisional $M$ types for group A streptococci. Emerg Infect Dis. 1999;5(2):247-53. DOI: 10.3201/eido502.990209 PMID: 10221877

5. National Center for Biotechnology Information U.S. National Library of Medicine. Basic Local Alignment Search Tool Bethseda, MD, USA. [Accessed 15 Dec 2016]. Available from: https://blast.ncbi.nlm.nih.gov/Blast.cgi.

6. Cummins A, Millership S, Lamagni T, Foster K. Control measures for invasive group A streptococci (iGAS) outbreaks in care homes.J Infect. 2012;64(2):156-61. DOI: 10.1016/j. jinf.2011.11.017 PMID: 22138601

7. Curtis SJ, Tanna A, Russell HH, Efstratiou A, Paul J, Cubbon $M$, et al. Invasive group A streptococcal infection in injecting drug users and non-drug users in a single UK city. J Infect. 2007;54(5):422-6. DOI: 10.1016/j.jinf.2006.10.004 PMID: 17116332

8. Efstratiou A, Emery M, Lamagni TL, Tanna A, Warner M, George RC. Increasing incidence of group A streptococcal infections amongst injecting drug users in England and Wales.J Med 
Microbiol. 2003;52(Pt 6):525-6. DOI: 10.1099/jmm.0.05167-0 PMID: 12748273

9. Lamagni TL, Neal S, Keshishian C, Hope V, George R, Duckworth G, et al. Epidemic of severe Streptococcus pyogenes infections in injecting drug users in the UK, 2003-2004. Clin Microbiol Infect. 2008;14(11):1002-9. DOI: 10.1111/j.1469-0691.2008.02076.x PMID: 19040471

10. Efstratiou ALT. Epidemiology of Streptococcus pyogenes. In: Ferretti JJ SD, Fischetti VA, editor. Streptococcus pyogenes: Basic Biology to Clinical Manifestations [Internet]. Oklahoma City (OK): University of Oklahoma Health Sciences Center; 2016-. Available from: https://www.ncbi.nlm.nih.gov/books/ NBK343616/.

11. Luca-Harari B, Darenberg J, Neal S, Siljander T, Strakova L, Tanna A, et al. , Strep-EURO Study Group. Clinical and microbiological characteristics of severe Streptococcus pyogenes disease in Europe.J Clin Microbiol. 2009;47(4):1155 65. DOI: 10.1128/JCM.02155-08 PMID: 19158266

12. Steer AC, Law I, Matatolu L, Beall BW, Carapetis JR. Global emm type distribution of group A streptococci: systematic review and implications for vaccine development.Lancet Infect Dis. 2009;9(10):611-6. DOI: 10.1016/S1473-3099(09)70178-1 PMID: 19778763

13. Krucsó B, Gacs M, Libisch B, Hunyadi ZV, Molnár K, Füzi M, et al. Molecular characterisation of invasive Streptococcus pyogenes isolates from Hungary obtained in 2004 and 2005. Eur J Clin Microbiol Infect Dis. 2007;26(11):807-11. DOI: 10.1007/S10096-007-0359-4 PMID: 17665233

14. Meygret A, Vincent P, Moullec S, Nacazume J, Adnani Y, Lavenier D, et al. Genome Sequence of the Uncommon Streptococcus pyogenes M/emm66 Strain STAB13021, Isolated from Clonal Clustered Cases in French Brittany. Genome Announc. 2016;4(4):eo0689-16. DOI: 10.1128/ genomeA.00689-16 PMID: 27445380

15. Athey TB, Teatero S, Sieswerda LE, Gubbay JB, MarchandAustin A, Li A, et al. High Incidence of Invasive Group A Streptococcus Disease Caused by Strains of Uncommon emm Types in Thunder Bay, Ontario, Canada. J Clin Microbiol. 2016;54(1):83-92. DOI: 10.1128/JCM.02201-15 PMID: 26491184

\section{License and copyright}

This is an open-access article distributed under the terms of the Creative Commons Attribution (CC BY 4.0) Licence. You may share and adapt the material, but must give appropriate credit to the source, provide a link to the licence, and indicate if changes were made.

This article is copyright of the authors, 2017. 